\title{
Action Research
}

\section{Improving Service Delivery of the}

\section{Finance and Budget Section ofJimma Teachers' College \\ (JTC)}

\author{
Debela Hunde Feyssa, Dunkana Nigusa,Kasaye Gutema, \\ Temesgen Mereba*
}

\begin{abstract}
Action research was conducted in May and June 2004 aimed at improving service delivery of finance and budget section of Jimma Teachers College. The data were collected by focal group discussion observation and actual experience of the researchers. The action research has disclosed that there were not efficient service in paying different payments like-evening, part time, fees ascribing to absence of incentives finance and budget section workers. Students' monthly payments were not done on time and this resulted in serious disciplinary problems on the students' side. These and other related problems were acted upon by dually planning between researchers, finance and budget section and customers. Following the action plan the result showed that there was implementation of the action plan. Thus, payments were executed on time and specified plan was also set for all types of payments officially known to the customers. The achievement of the action research was left for sustainability to the administrative departments of the college to enhance the effective educational finance.
\end{abstract}

Jimma Teachers' College Instructors, Jimma,Ethiopia 


\section{Introduction}

In order to coordinate and facilitate college based organizational change and planning process college managerial personnels must understand and have expertise in three areas (1) problem solving and planning cycles of the college from organizational perspective (2)improved educational resources utilization (3)reach specific goals that improve service delivery (Quinby,1985). Furthermore, the intervention stage in which the development of the organization and its members capacity to implement the intervention action plan. According to BSL (2004) strong interpersonal communication skills are essential since much of an administrative personnels job involves working and collaborating with others. On top of this, it is explained that, higher education administrators also direct and coordinate the provision of students services including financial services. While doing this worker must first prove themselves in their current jobs.

Educational personnels should also understand that they are organizational partners whose goal is to meet and surpass the needs of the academic mission and be the needs of the academic mission and be recognized for providing outstanding service that customers such as students, instructors, and other workers). Working together in promoting mutual respect, fair treatment, involvement and personal accountability, take pride to their work and are committed to the concept of continuous improvement of service delivery (Lee, 2004)

Listening and collaborating on issues and problems, non- blaming and value each other while giving service (Lee, 2004). There should be willingness to accept change and liberate customers from bureaucracy. All the efforts made by all educational personnels need to be integrated to fulfill the educational goals as specified by each specific institute. Jimma Teachers College is 
also one of such institutes to be looked as to how educational services are delivered to achieve the goals of the college. Hence the research is targeted to take some actions to enhance service delivery in specified section.

\section{Rationale}

One of the services giving sections of Jimma Teachers' College is the finance and budget section. But were problems of giving effective service from this section to customers. Customers were often heard and observed complaining that sometimes salary payment started on Friday afternoons which were followed by Saturday and Sunday which are off-days and that there is no clear programme as to when to pay for the administrative and teaching staff. When students' monthly payment took place, there was crowdedness, too much noise and disturbance because of lack of clear and systematic programme and enough preparation. Most of the time payment of tutorial, evening programme for the participant is delayed. It is also observed that, the office in which the section gives service was crowded with piled and piled financial documents and also with more number of workers of the section and in short there is office organization problem. Therefore, it was imperative to interfere with this issue at least by some managerial action, which should be based on practical research endeavor in general. This action research project designed to improve the problems stated above in relation to the finance and budget section of the college to enhance effective utilization of educational finances.

The purpose of this action research was to enable the finance and budget section of Jimma Teachers' College render timely, quality and programmed service for workers and students of the college and to 
improve the office organization of the section.

\section{Performance Indicators}

1. Service delivery in workers monthly salary payment, in students monthly payment, in tutorial and evening payment would be improved, (2) average satisfaction of customers would be realize with the improvement of the service delivery; (3) undelayed service would be observed and(4) office Organization would be improved.

\section{Methods}

Tools used were focal group discussion along with personal observation and practical experiences of the researchers as management affiliated personnels in the college. Data were gathered through interview and personal observations. To gather data regarding the service delivery of finance and budget section of Jimma Teachers College, the researchers interviewed some concerned individuals. Furthermore, as the investigators are the members of the college we have used had our own personal observation, practical experiences and judgment.

Accordingly four groups of interviewees were interviewed. These four are: students, instructors, administrative workers and workers of the section head of the section and administrative and finance head.

A total of eighteen persons (11 females and 7 males) were involved. The Action plan for the action research is shown in Appendix 1.

\section{Result}

Based on the indicated problem such as delayed service in monthly payments of students, problem in settling accounts, undisciplined manners of students during monthly payments interviews were arranged. The interviews were conducted by arranging timetable, which is suitable to respondents and interview processes as well. In the interview representatives of students from first year, representatives of 
instructors, workers of finance and budget section, representatives of administrative workers were involved.

\section{Interview with instructors, administration workers and workers of}

the section

1.The responses to question what would you like to comment regarding salary payment have shown that, salary payment was the least problematic payments. A minor point is that most often the section pay salaries are paid on Fridays and sometimes in the afternoon.

2. Concerning settling accounts, the respondents stated that there are certain problems. These include favoritism i.e. some workers of the section neglect some people while they facilitate the situation for others. Moreover, it was pointed out that at times payment of par-time might be delayed because of unreasonable bureaucracy. This is responded by all interviewees.

3. The interviewees also pointed out that the delay in effecting the payment of evening and par-time workers is quite apparent. The workers of the section suggested that the absence of incentives i.e. additional payments than normal salary discouraged them not to render effective services.

4. The interviewees have also disclosed that evening students are subject to lots of mistreatments when they pay their tuition fees. Accordingly, the students will be made to stay the whole day in queue for there is no detailed program; workers of the section do not treat the students politely.

5. Regarding monthly payment of regular students, all interviewees confirmed that it is not effected effectively and undisciplined processes were practically observed.

The students' misbehavior has been mentioned as part of the cause. This was checked that some students do not turn up at the right time: they do not have tolerance and sometimes they even insult workers of the section and they do not even bring the necessary papers, such as 
identification cards and registration slips.

The workers of the section including the head of finance and budget and administrative and finance head have admitted that most of the issues raised above are apparent. Furthermore, the workers of the section pointed out that most of the problems arise from organizational problems of the section, i.e. the section is under staffed, students have lots of discipline problems such as not coming with necessary documents: they also insult workers of the section. The workers of the section have also admitted that they do not endeavor to the best of their capacity due to luck of additional payment.

\section{Interview with Students}

Seven students which were considered key person were purposely selected for this interview of action research.

The interviewed students said that they are not satisfied with the activities of the section. The students complained about the delay of their monthly payment. They said that sometimes, they will be paid after 3435 days. Consequently, the students will face serious problem i.e. they have nothing to eat, they failed to pay their house rent on time. The students again complain about their mistreatment by some workers of the section.

Further still, the students went on pointing out that due to the lack of information regarding the schedule of the section, some instructors give quiz on students' paydays. According to students response some instructors also try to punish students who miss classes when collecting money. This is the point on which further research and detailed action need to take place throughout 2004/ 2005 academic year. The staff of the college also witnessed that there is improvement in students' discipline during their monthly payments. However, it needs continuous follow up for sustainability of the improvement for 
the betterment of teaching learning processes.

\section{Action Taken}

Based on the problems identified action plan is prepared to alleviate the problems identified by this research. The action plan was set dually by the section and researchers with specified timetable to work on.

The budget and finance section was advised to work on the specific time table to give all services on time i.e. undelayed. Researchers were perusing the implementation of the plan as specified in the dual plan. Accordingly some of the basic issues included in the action plan are:

(1) Salary payment of instructors and administrate workers should be effected according to schedules set specifically. Besides, this payment shouldn't start in the afternoon and off days.

(2) The bureaucracy for pertinent problems during settling accounts should be eliminated. Accordingly, one person will be assigned to implement it. This

\begin{abstract}
same person shall keep the records or he will have to supply documents for the person who wants to settle accounts. This also needs further follow up for sustainability by administrative personnels of all levels in the college management which really addressed by the researchers by convincing them during the action research.
\end{abstract}

(3) The workers of the finance and budget section do not have to ascribe the delay of payment for par- time and evening extension classes to the absence of incentives. Consequently these workers have been given clear guidelines that they need to work to the maximum of their capacity. The absence of such incentives needs high-level check as to how it will be paid and for whom, when and for what.

(4) There were quite lots of allegations regarding the collection of tuition fees from evening/extension students. A new 
plan which clearly shows when, where and by whom the fees will be collected has been designed. According to this plan the students will be informed a head of time when they are to pay their monthly fees. This was implemented for last monthly payment of 2004 .

(5) All interviewees have confirmed that the monthly payment of regular students is accomplished in a mess similar to collection of monthly fees of evening students plan of action has been designed and acted up on. This has shown some improvement. Still persuasion is imperative for its maximum implementation and improvement.

\section{Major Out Comes}

So far, a considerable change has been made as a result of this action research. Some of these are: the salary payment of teachers and other administration staff has been acted up on and the have received feed back from customers that what has been done is quite appreciable.
Administrative workers and teaching staff used to collect their salary at the same time but now we have changed that i.e. one group collected in the morning; the other in the afternoon. As a result, there were no crowding or waiting in long queues. There has been some progress regarding settling of accounts. At least the workers of the section were more transparent and willing to help those who turned up for reconciling accounts.

There were some pays for evening extension classes after we conferred with the finance and budget workers. The workers of finance and budget have admitted their former weakness for not effecting this payment in time. However the problem with this payment is that the section of continuing education itself retards the process, otherwise the workers of finance and budget will accomplish it immediately. Evening students did not wait for a long time when they paid their tuition fees last time. They knew when they were to pay- the specific 
time and the facilitator. So, we can say, their problem has already been partly alleviated.

Regular students also managed to collect their last monthly payment peacefully and on time. This was so because it was accomplished according to the designed plan. There were no quarrellings, almost no major complaints, as each student turned up at the right time, should show their necessary documents. Therefore, students have received their monthly payments in the order of streams and departments in alphabetical order. For 2004/2005 academic year instructors will be informed a head of time when their students will collect their monthly payment to put their facilitation role. This has been on being effected by putting a prior notice on college notice board officially since the identification of the problem and dually agreed action plan.

A further point is the majority of the budget for running cost is being completely used according to the plan. Additional budget has also been requested. Furthermore, the action research has capacitated the management to speed up their effort in utilizing budget efficiently. Considerable progress has been made in every issue raised.

Part of the action taken to improve office crowdness of the section was assigning two cashers to different offices. This has partly reduced crowdness and reduced ascribing delay of activities on one another. This has somehow increased accountability on the side of the workers of finance and budget section of Jimma Teachers College.

\section{Conclusions}

Focal group discussion with workers, heads of finance and budget section and customers has shown that salary payment is the least alleged payments. Most often, salaries are paid on Fridays and sometimes in the afternoon. On top of this, settling accounts has been bureaucratized simply by 
negligence. Payment of evening and part time were also delayed because of absence of incentives. Most importantly regular students monthly payment is full of bureaucracy and undisciplined actions and is delayed most of the time. Furthermore, collection of evening tuition fees were very confused in some instances and ascribed to absence of incentives. Inspite of all the indicated problems, the action research has largely alleviated the problem some how because of planned action taken by section workers, researchers and customers.

\section{Recommendations}

The achievement need to be sustained by the continuous followup and monitoring scheme. On top of this, the budget and finance section office need to be divided in to two sub- section i.e. internal revenue and project and recurrent budget sub- section. The rooms also need to be divided with necessary document and human resources. This was partly done but there should be persuasion of the remaining issue in this regard by the college administration department. The outcomes of this action research are also submitted to the administrative department of the college for sustainability and follow up to the efficient utilization of educational finance for the enhancing academic activities of the college. The finance and budget section should work the maximum of their capacity by committing themselves to render genuine service to customers. The office organization already started also need be promoted in the way it will be suitable for services.

\section{References}

Bureau of Labor Statistics (BLS) U.S

Department of labor, occupational out look Handbook,2004-05 edition, education Administrators, on the internet at http://www.b/s. gov/oco/ocos007 htm pp, 1-9 
Improving Service Delivery of the Finance and Budget Section

Debela H. et al 105

Lee, $\mathrm{R}$ (2004). Administrative

systems and Finance facilities

Development and operations,

human resources, University

Computing

and

Telecommunications and University

police. San Jose State University,

Washingtone Square pp.1-3
Quinby,W. (1985.) Improving the

place called school:

Educational leadership,

$42,17-21$.

Kossek, E.E, and Label, S.A ( 2001).

Human Resource management:

Transforming. The workplace:

Newelhi. PP1-17

\section{Appendix 1}

\section{Action plan for the Action Research Project}

\begin{tabular}{|c|c|c|c|c|}
\hline No & Action to be taken selection & Responsible person & By when & Out come review \\
\hline 1 & $\begin{array}{l}\text { Selection of focal group for discussion by preferential } \\
\text { sampling technique }\end{array}$ & All researchers & 26/8/96 E.C & \\
\hline 2 & $\begin{array}{l}\text { Discussion (Interview) with the selected persons to identify } \\
\text { and concretize the problem of service delivery (at least } \\
\text { each interview person), }\end{array}$ & All researchers & $27 / 8 / 96$ & \\
\hline 3 & $\begin{array}{l}\text { Discussion with the finance and budget section about the } \\
\text { problem and refining for action }\end{array}$ & Debela \& Temesgen & $30 / 8 / 96$ & \\
\hline 4 & $\begin{array}{l}\text { Mutual researchers customer and the section planning for } \\
\text { improvement of service delivery. }\end{array}$ & All researchers & $3 / 9 / 96$ & \\
\hline 5 & Action on identified issues & $\begin{array}{l}\text { Finance and budget } \\
\text { and investigators }\end{array}$ & $4-29 / 9 / 96$ & \\
\hline 6 & $\begin{array}{l}\text { Evaluation of the action with other customers selected from } \\
\text { the college. }\end{array}$ & $\begin{array}{l}\text { Finance and budget } \\
\text { and investigators }\end{array}$ & $30 / 9 / 96$ & \\
\hline 7 & Report writing & $\begin{array}{l}\text { Temesgen,Kasaye } \\
\text { and Debela }\end{array}$ & $1-4 / 10 / 96$ & \\
\hline 8 & Editing & Debela & $5 / 10 / 96$ & \\
\hline 9 & Presenting the finding of the action research in the college & All researchers & $7 / 10 / 96$ & \\
\hline
\end{tabular}

